\title{
Extending the Shelf Life of Strawberries by the Sonochemical Coating of their Surface with Nanoparticles of an Edible Anti-Bacterial Compound
}

\author{
Belal Abu Salha * and Aharon Gedanken

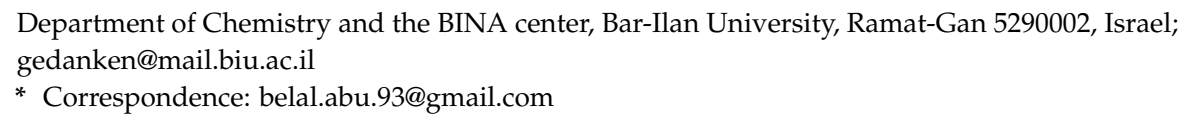

Abstract: The current paper presents the coating of harvested strawberries with edible nanoparticles of Chitosan. The NPs were formed by the application of ultrasonic waves on an acidic solution of chitosan. In a one-step process the nanoparticles were created and subsequent to their formation they were deposited on the strawberries surface. The shelf life of the NPs coated was compared with the deposition of the same amount of non-sonicated chitosan, i.e., coating of individual chitosan molecules on the fruit. The characterization of the coated fruits was carried out by monitoring the weight loss. TSS (total soluble solids), pH, TA (titratable acidity), and Vitamin C. Finally, the freshness of the strawberries was determined by eye observation. In addition, the characterization of the chitosan NPs was also conducted in this study by (DLS) dynamic light scattering and (SEM) scanning electron microscopy.

Keywords: Sonochemistry; chitosan; nanoparticles; edible coating; strawberry

Citation: Abu Salha, B.; Gedanken, A. Extending the Shelf Life of Strawberries by the Sonochemical Coating of their Surface with Nanoparticles of an Edible Anti-Bacterial Compound. Appl. Nano 2021, 2, 14-24. https://doi.org/ 10.3390/applnano2010002

Received: 11 November 2020 Accepted: 21 December 2020 Published: 4 January 2021

Publisher's Note: MDPI stays neutral with regard to jurisdictional clai$\mathrm{ms}$ in published maps and institutional affiliations.

Copyright: (C) 2021 by the authors. Licensee MDPI, Basel, Switzerland. This article is an open access article distributed under the terms and conditions of the Creative Commons Attribution (CC BY) license (https:// creativecommons.org/licenses/by/ $4.0 /)$.

\section{Introduction}

Fruits and vegetables which are perishable soon after harvest, require proper packaging and storing if not consumed immediately $[1,2]$. The high decayable fruits and vegetables prompted researchers to look for new approaches to elongating shelf life [1]. Strawberries are considered a type of fruit with great economic importance worldwide because of their taste and also their health benefits [3,4]. Strawberries have a significant nutritional value because they contain minerals and vitamins, and a variety of flavonoids and phenolic acids with biological properties, for instance antioxidant, anticancer, and anti-inflammatory activities [5,6]. However, strawberries have a noticeably short life after harvesting with a high rate of decay, which reflects a mechanical deterioration, softer texture, and contamination by pathogens during storage or transport [7]. Edible coatings have essential importance in maintaining food quality and can be applied as a thin layer on the surface of the food that acts as a barrier to gases $\left(\mathrm{O}_{2}, \mathrm{CO}_{2}\right)$, vapors, and solutes. [2,8]. Edible coatings can potentially extend the shelf life by controlling the mass transfer, moisture, flavor, and aroma losses and by maintaining the external appearance of the food $[9,10]$. Modification of the metabolism of fruit tissues by controlling respiration rate, elongating the shelf life during the storage period, firmness maintenance, and preventing microbial growth which counts as an important functional advantage of using the edible coatings [11]. Edible coatings which are based on natural biopolymer such as lipids, polysaccharide, and protein, constitute an innovative development on the concept of food preservation. Chitosan (CS) a natural biopolymer (poly $\beta-(1,4)$-acetyl-D-glucosamine) is considered as cationic polysaccharide in its active form, biodegradable compound, non-toxic for human health and eco-friendly material [12] CS is considered a highly-biocompatible substance which is characterized by its biological uniqueness as a preservative for fruits and vegetables [13-15]. CS has antimicrobial activity against fungi, bacteria, and viruses which 
make it an alternative compound to conventional fungicides because of its capacity to keep over fruit surfaces free of residues [16] Chitosan-based edible coatings are considered the best conservative coatings for different types of fruits, which leads to structural protection that prevents biological, chemical, and physical deterioration [17]. Coating Chitosan on fresh produce plays an important role in maintaining the quality and safety of the modified fruit [18]. Edible coatings depend on various parameters such as type, amount, viscosity, and surface tension. Furthermore, the coating method also affects the quality and efficiency of the coating [19-21]. Particles made of natural biopolymers can be prepared, ranging in size from 10 to $1000 \mathrm{~nm}$ [22]. Particles have physical and chemical properties due to their capacity to controlling the particle size up to the level of NPs and surface adhesion. Nanoparticles have higher antibacterial activity than individual particles when they are applied on the surface of fresh produce during the cold storage period [23]. This could be due to the larger surface area of nanoparticles and their higher affinity for bacterial cells [24]. CS NPs is a natural material with excellent physicochemical properties [25], because one nanoparticle contains thousands of chitosan molecules. The sonochemical method can be used to prepare CS NPs [26]. Moreover, the application of Ultrasonic waves have been proven as an outstanding technique for coating surfaces with nanoparticles on ceramic, cotton [27], polymeric, metallic, glass [28], textiles [29,30], and even paper [31]. The sonication of a solution, aqueous or organic, leads to the formation of nanoparticles (NPs) of the solute. Moreover, in previous studies food preservation materials were used to elongate the shelf life of strawberries coating with CMC-Guar gum- $\mathrm{Ag}^{\circ} \mathrm{NC}$ (NanoComposite) films [32], or films of pectin (PEC) + nanoparticles [33], or eugenol (EG) loaded with core-sheath PVP/shellac fibrous films which were prepared by coaxial electrospinning technology that was employed for this purpose [34]. Chitosan was already involved in this goal where films with different molecular weight and chitosan/corn amylose/cinnamaldehyde films were used for the packaging strawberries to extend their shelf life [35]. In addition, strawberries were dipped in different aqueous solutions like $\mathrm{CaCl} 2$ or salicylic acid (SA) in different concentrations, solution of N-succinyl chitosan (NSC) immobilized on lysozyme and sodium alginate solution combined with $\mathrm{ZnO}$ NPs were applied as an edible coating to increase the shelf life of post-harvest [36-39]. Also, techniques such as atmospheric cold plasma (ACP) and electrostatic spraying (ES) were used as efficient techniques for strawberry preservation $[20,40,41]$. The purpose of this study was to demonstrate the feasibility of the sonochemical method to form chitosan NPs and to coat them on strawberries. The sonochemical method employed in the current investigation was primarily aimed to elongate the shelf life of strawberries. The coating of the nanoparticles of chitosan, organic water-soluble compound was conducted without using any binding agents. The novelty of the current study is in the formation of nanoparticles of the preservation material, and its comparison with the same amount of separated chitosan molecules. In addition, a unique coating method was used for this goal. The manuscript emphasizes the effects of edible coating, chitosan NPs, on the quality and shelf life of strawberries as described in the Scheme 1 below.

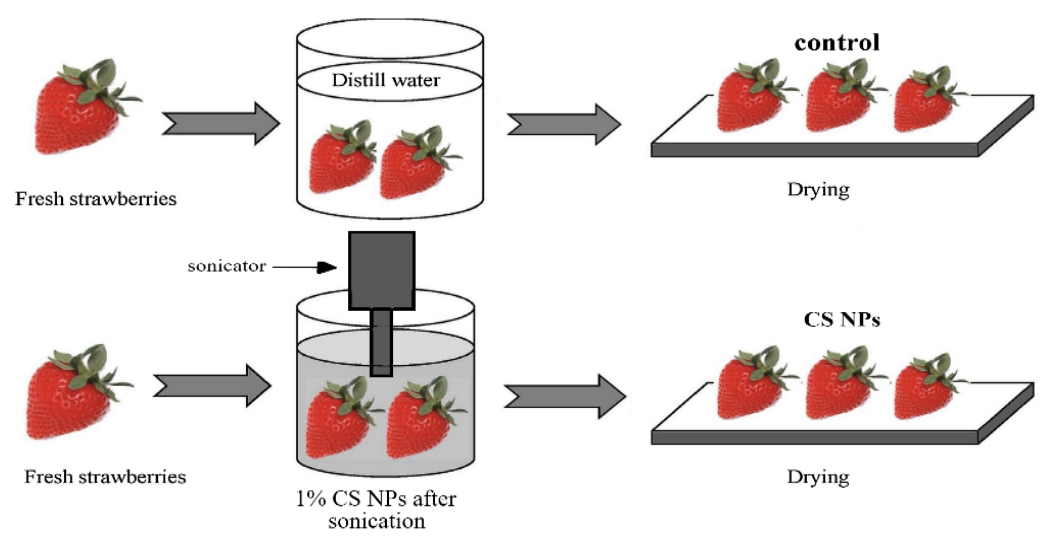

Scheme 1. CS NPs shelf life effect on fresh strawberries. 


\section{Materials and Methods}

\subsection{Fruit Samples}

Fresh strawberries (Fragaria ananassa) were purchased from a local market. These strawberries were carefully selected for uniformity in size, color, external appearance, and free of visible defects and decay. The fruits were transported to the laboratory and coatings were applied.

\subsection{Coating Compounds}

Low molecular weight CS (Chitosan) (15 kDa) were purchased from Sigma Aldrich, as well as $1 \%$ aqueous acetic acid $(v / v)$, deionized water was used for preparation of the solutions.

\subsection{Preparation of the Edible Coating Solution}

For the formation of Chitosan NPs, CS (300 mg) were dissolved in $30 \mathrm{~mL}$ of $1 \%$ aqueous acetic acid solution and then deionized water were added to obtain $300 \mathrm{~mL}$, to form $0.1 \%$ (wt.) of chitosan solution. The solution was stirred by a magnetic stirrer until fully dissolved of CS for $24 \mathrm{~h}$. To prepare NPs of CS a high-intensity ultrasonic Ti horn (20 KHz, $750 \mathrm{~W}$ at 30\% efficiency) was immersed and operated for $30 \mathrm{~min}$. The solution was cooled to $45^{\circ} \mathrm{C}$ under cooling condition during the sonochemical process and then cooled to room temperature $25^{\circ} \mathrm{C}$ before the coating takes place. The same process was applied for distilled water as a reference coating.

\subsection{Coating Method}

The strawberries were washed with distilled water for 2 min and dried at room temperature before the coating process of $2 \mathrm{~h}$. The strawberries were then dipped in the edible coating solution undergoing sonication for 30 secs to enable the chitosan nanoparticles to be glued to the surface of the fruit and create a uniform film. For control the same process of immersion is done for strawberries which have been dipped in distilled water. Also, the same process is done with CS solution that did not undergo sonication, to check if coating with NPs of chitosan have any advantage over the NPs in extending the shelf life and maintaining the quality of the strawberries. The strawberries were dried at room temperature for $3 \mathrm{~h}$ and were subsequently stored at $4{ }^{\circ} \mathrm{C}$ and $80-85 \%$ relative humidity for 15 days of cold storage. Quality measurements were performed at $0,3,6,9,12$, and 15 days, respectively. The samples assessment was done at least in triplicate.

\subsection{Characterization of Chitosan Nanoparticles}

\subsubsection{Dynamic Light Scattering (DLS)}

Particle size distribution of the NPs of chitosan after sonochemical process were measured by a DLS instrument (Malvern, UK) to confirm the formation of CS NPs in the solution [22]. The analysis was carried out at scattering angel of $90^{\circ}$ at temperature of $25^{\circ} \mathrm{C}$ using nanoparticles dispersed in distilled water (300 $\mathrm{mg}$ of sample was dissolved in $300 \mathrm{~mL}$ of $1 \%$ acetic acid solution and then sonication is done in a high-intensity ultrasonic Ti horn). The average particle size of NPs is reported as well as the polydispersity index (PDI).

\subsubsection{Scanning Electron Microscopy (SEM)}

The morphology of the surface and the size of the nano-edible coating on the surface of the strawberries was characterized by environmental scanning electron microscopy (E-SEM) using (Quanta FEG 250 of FEI) device at $5 \mathrm{KV}$.

\subsection{Physical and Chemical Properties of Strawberries}

Weight loss was investigated by weighing the strawberry before and during the storage period and weight loss percentage calculated by the following equation.

$$
\text { Weight Loss }(\%)=\frac{W_{i}-W_{f}}{W_{i}} \times 100
$$


When $\mathrm{W}_{\mathrm{i}}$ is the initial weight and $\mathrm{W}_{\mathrm{f}}$ is the final weight of the tasted strawberry during the storage period at time $(t=0,3,6,9,12$, and 15 days). Group of strawberries were homogenized by blender and measurement of Total soluble solids content (TSS, Brix) was gauged by using a handheld refractometer (REF113 Brix/ATC 0-32\%) which measure the refractive index, and the results were expressed as ${ }^{0} \mathrm{Brix}$. Measurements of $\mathrm{pH}$ were conducted with a pH-meter (Mettler Toledo Sevenmulti). Titratable acidity (TA) of the samples were assessed using a $\mathrm{pH}$-meter and a titration of each sample was performed with $0.1 \mathrm{M} \mathrm{NaOH}$ to an end point of 8.2 and the results were expressed as gr of citric acid per $100 \mathrm{~g}$ of sample. In addition, the L- ascorbic acid concentration in homogenized blended strawberries was determined by redox titration using iodine solution and expressed as ascorbic acid content in $100 \mathrm{~g}$ of sample [10,36,37].

\subsection{Sensory Acceptance}

Decay rate a damage that caused by deterioration symptoms such as, mold growth, bacteria, and inhibition of enzymatic processes on fresh produce, were appreciated by visual examination that based on general visual attraction, color and visible structural completeness, according to the following scale: 1 = no damage; $2=$ minor damage below $25 \% ; 3=$ moderate damage between $25 \%$ and $50 \% ; 4=$ drastic damage between $50 \%$ and $75 \% ; 5=$ totally damage between $75 \%$ to $100 \%$. Strawberries scored below 2 was considered acceptable [3].

\section{Results and Discussion}

This paper aims to prove that embedding edible NPs of chitosan on the surface of strawberries by a one-step ultrasound assisted procedure can increase their shelf life at cold preservation.

Characterization of chitosan NPs- To verify the validity of prepared chitosan NPs, the sonicated particles were characterized by DLS and SEM.

\subsection{Dynamic Light Scattering}

To certify the presence of the CS NPs in the solution and evaluate their size division, the solution of CS NPs was analyzed by the DLS method after the sonication. The results show that the chitosan particle size before sonochemical process ranged above $1000 \mathrm{~nm}$ Figure $1 \mathrm{~A}$ as compared to the size of CS NPs at selected concentration that ranged between $100-600 \mathrm{~nm}$ as shown in Figure 1B.

\subsection{Scanning Electron Microscopy}

The surface morphological structure of the strawberries coated with CSNPs was examined by E-SEM method after performing the sonochemical process on the chitosan $1 \%$ solution as a coated sample and on the distilled water as a control sample. The results show that the nanoparticles size of CS NPs that were distributed on the fruit surface was around 200 to $600 \mathrm{~nm}$ Figure 2. In contrast, the control samples showed no nanoparticles on the surface of the strawberries.

\subsection{Physical and Chemical Properties}

Strawberries weight loss is a significant index that reflects the respiration rate and humidity between the strawberry and their surroundings. Weight loss increased throughout the cold storage period also for the sample coated with chitosan NPs and uncoated strawberry with significant differences between the two cases. As shown in Figure 3 CS NPs coatings on strawberries significantly delays the weight loss comparing to the uncoated samples (control). The weight loss of strawberries dipped in a non-sonicated chitosan solution is also monitored and presented in blue curve of Figure 3. The comparison between the three curves in Figure 3, demonstrate that the use of CS particles on the surface is the best coating in terms of weight loss. The results show that during storage period strawberries coated with CS NPs have the most effective trace in reducing weight loss $31.18 \%$ compared to the control with $64.14 \%$, and the individual CS with $37 \%$ weight loss. 


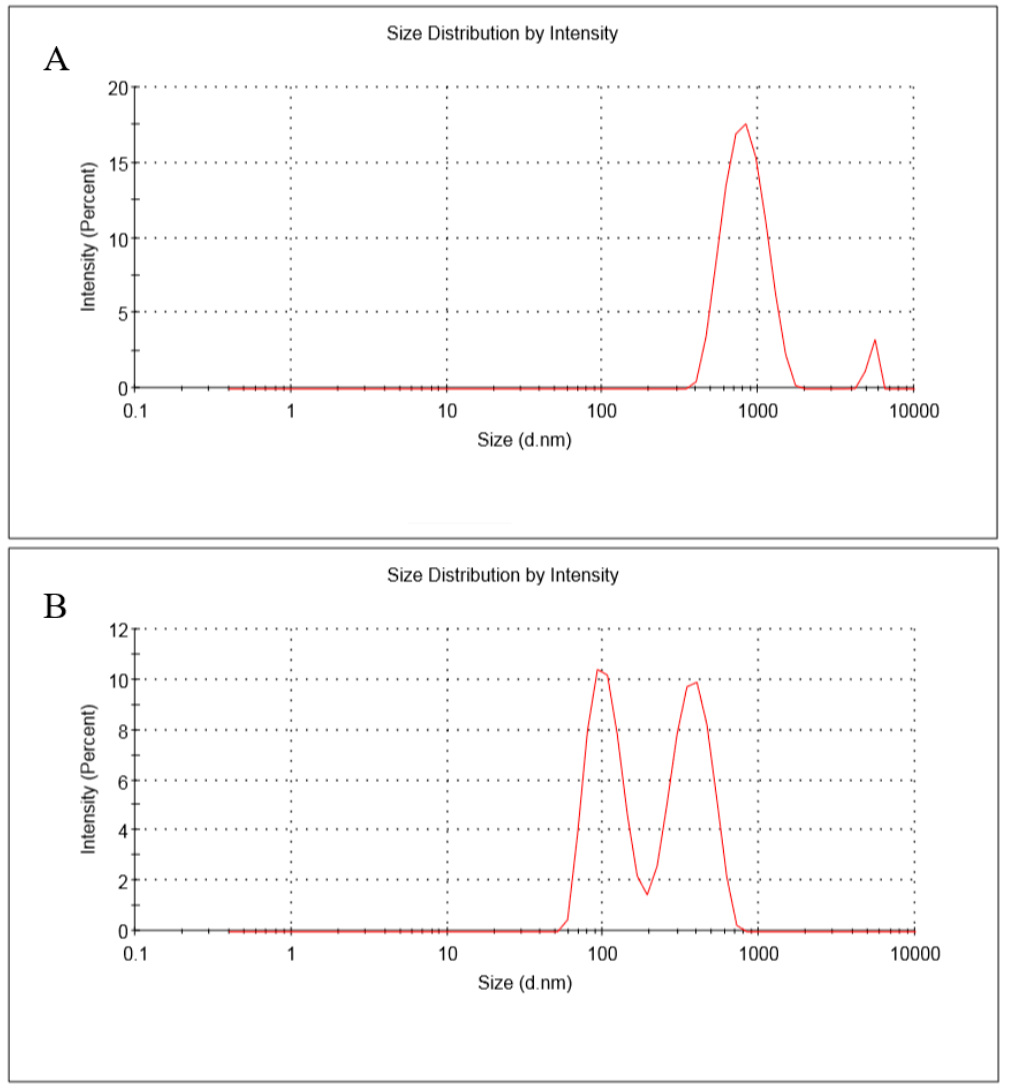

Figure 1. Dynamic light scattering (DLS) analysis of chitosan solution before (A) and after (B) sonication.
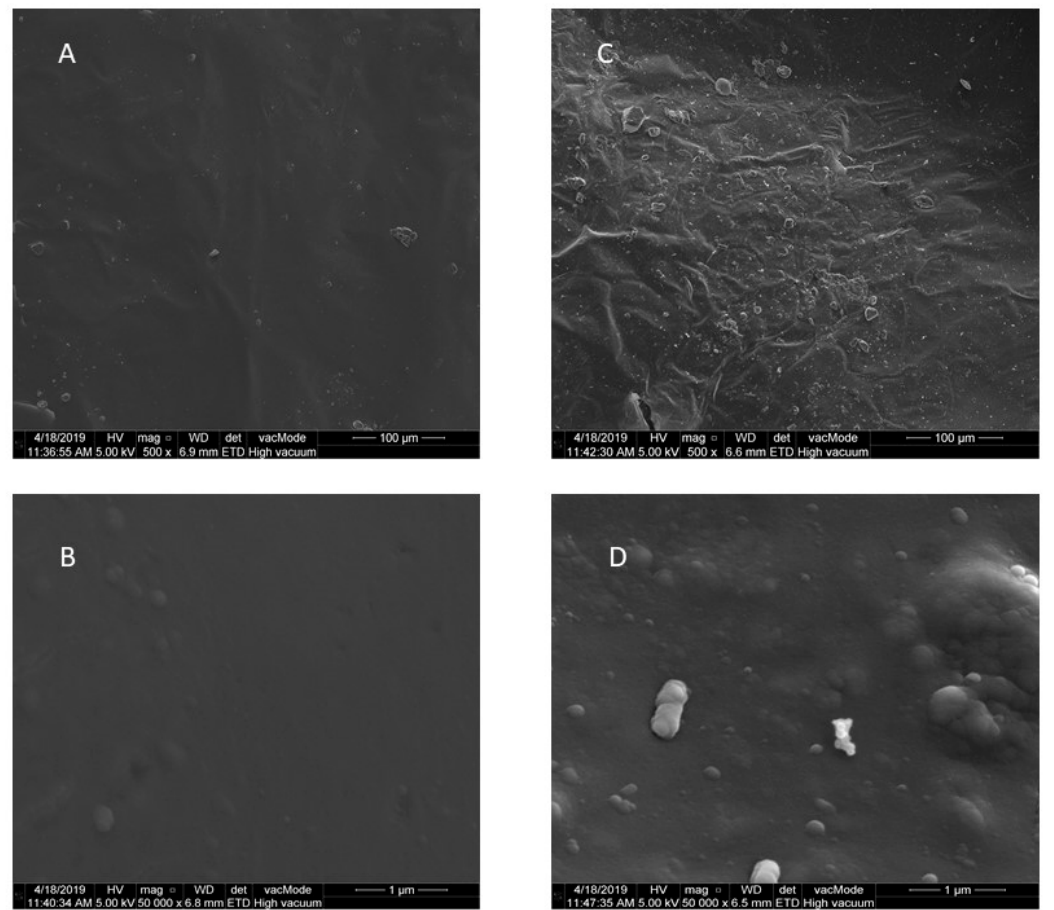

Figure 2. Scanning electron microscopy (SEM) images of (A) control sample of strawberry without coating (magnification 500×), (B) control sample at (magnification 50,000×), (C) strawberry coated with CS NPs after sonication (magnification 500×), (D) strawberry coated with chitosan (CS) nanoparticles (NPs) at (magnification 50,000×). 


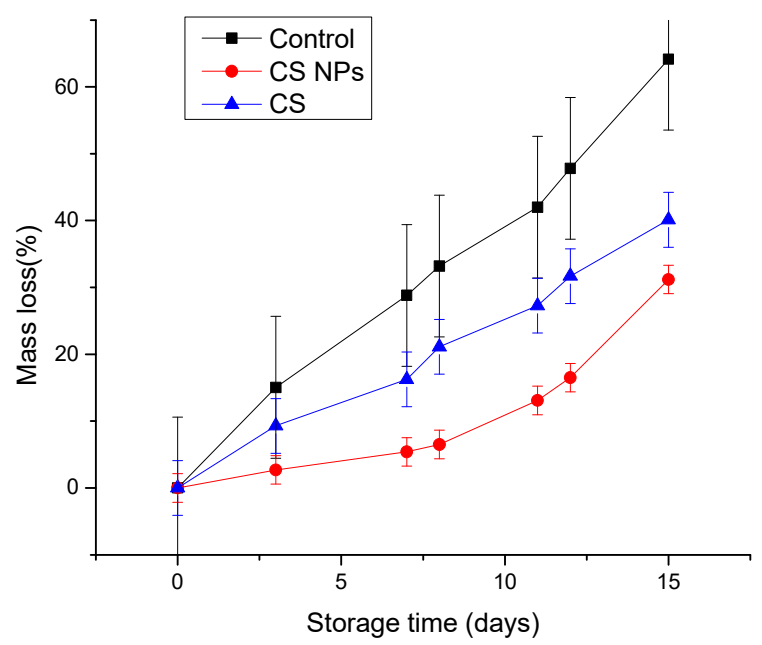

Figure 3. Effect of CS and CS NPs edible coatings on the mass loss of strawberries stored at $4{ }^{\circ} \mathrm{C}$ and $80-85 \%$ relative humidity (error bars indicate standard deviation).

Total soluble solid (TSS) are related to the degree of maturity and basic metabolic reaction that increase the sugar content throughout storage period. TSS is substantial parameter that affects the quality of postharvest fruit and acceptance of consumer. High TSS value is preferred. The TSS of coated strawberries decreased slightly during the storage while this parameter dropped sharply in control strawberries. The TSS content of coated strawberries maintained a high value during the 15-day storage period (10.1 to 9.1\%) compared to control fruits (9.8 to $7.1 \%$ ) (Figure 4 ).

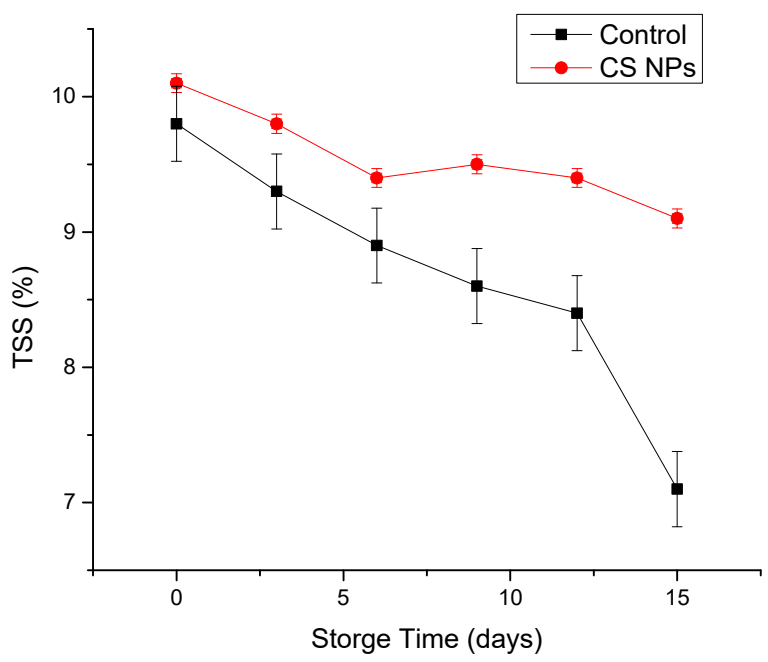

Figure 4. Changes in total soluble solids (TSS) of strawberries during the storage period at $4{ }^{\circ} \mathrm{C}$ (error bars indicate standard deviation).

The $\mathrm{pH}$ reflects the changes of organic acid content in fresh fruit during storage. The $\mathrm{pH}$ value increased during the storage period in general, which was corelated to fruit aging and microorganisms growing in an acid substrate when their metabolic activity made the medium less acidic with high $\mathrm{pH}$ value. The changes in $\mathrm{pH}$ value of strawberries coated with CS NPs and uncoated strawberries during the 15 days of cold storage at $4{ }^{\circ} \mathrm{C}$ are shown in Figure 5.

Titratable acidity (TA) reflects the change in the percentage of citric acid in fresh fruit since citric acid constitutes a major part of the acid in strawberries. However, using of CS NPs as an edible coating does not affect the TA of strawberries significantly during the 
storage period, but the TA of control (uncoated) strawberries decreased slightly at the end of storage period Figure 6.

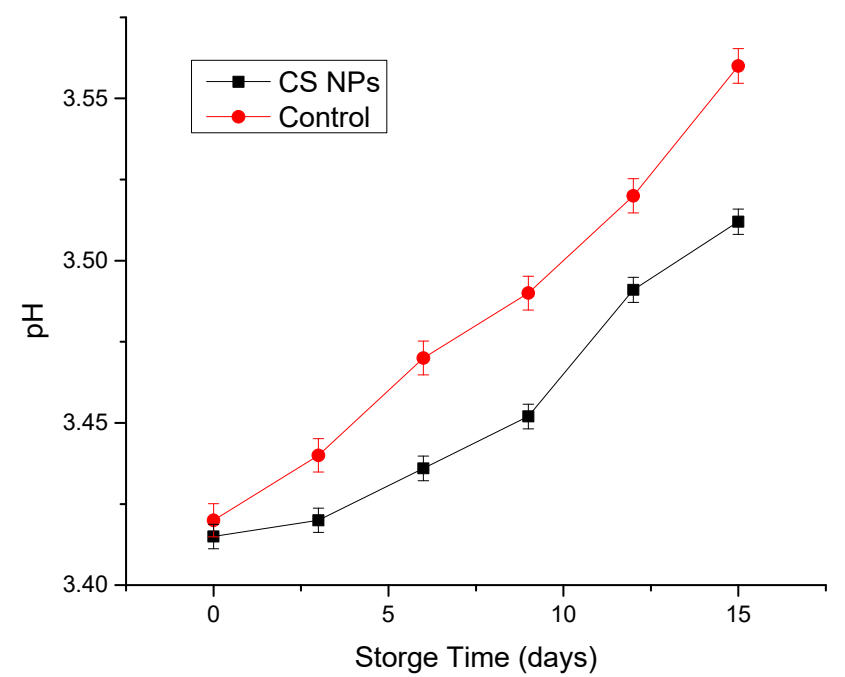

Figure 5. Effect of edible CS NPs on the $\mathrm{pH}$ of strawberries stored at $4{ }^{\circ} \mathrm{C}$ (error bars indicate standard deviation).

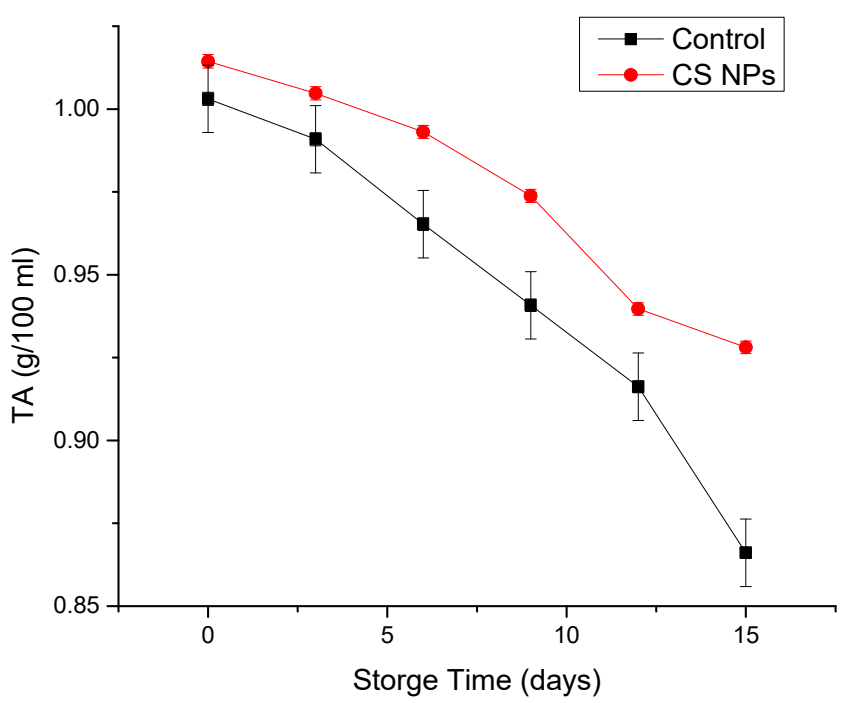

Figure 6. Effect of CS NPs edible coating on the titratable acidity (TA) of strawberries during the storage at $4{ }^{\circ} \mathrm{C}$ (error bars indicate standard deviation).

L-ascorbic acid (Vitamin C) is a necessary nutrient needful to maintain human health. Strawberries fruit have a comparatively high concentration of vitamin $C$, which is around $40-70 \mathrm{mg} / 100 \mathrm{~g}$ strawberries. However, vitamin C is easily degraded during storage period. The L-ascorbic acid concentration in strawberries at this research ranged from 56.35 to $56.79 \mathrm{mg} / 100 \mathrm{~g}$. Results shown in Figure 7 indicate a strong reduction of the L-ascorbic acid in the uncoated (control) strawberries $20.03 \mathrm{mg} / 100 \mathrm{~g}$, after 15 days of cold storage. And after these time strawberries coated with CS NPs kept high value of L-ascorbic acid $43.54 \mathrm{mg} / 100 \mathrm{~g}$.

Vitamin C consists of l-ascorbate and dehydro-l-ascorbic acid (DHA) is chemically considered to be one of the simplest vitamins. Plants can synthesize ascorbate, accumulating it at up to millimolar concentrations. The oxidation reactions involved are effectively reversible in plants owing to the presence of DHA reductase and monodehydroascorbate reductase. DHA can then be further oxidized to a range of products or hydrolyzed to form 
diketogulonate (DKG), both these reactions representing a permanent loss of vitamin C from the plant tissue which occurs with the strawberries as well [42].

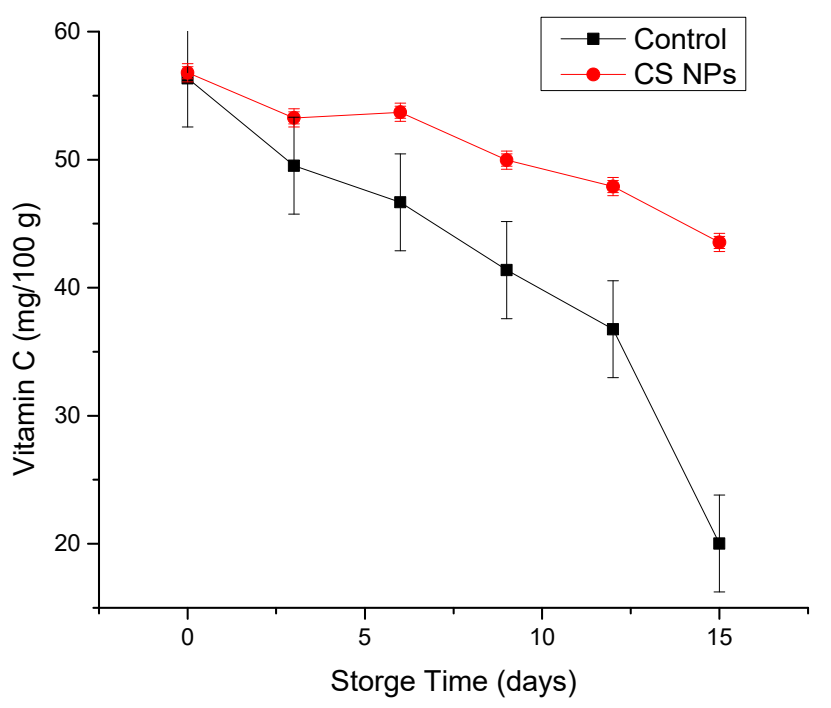

Figure 7. The effect of CS NPs, on the content of L-ascorbic acid (Vitamin C) of strawberries during the cold storage at $4{ }^{\circ} \mathrm{C}$ (error bars indicate standard deviation).

\subsection{Sensory Acceptance}

The Decay rate reflects the occurrence and severity of mold. In an initial evaluation of coated CS NPs and uncoated strawberries presented source of 1 , suggesting that the strawberry will not be damage by molds and enzymatic processes. Nevertheless, decay rate increased significantly in control fruits (decay rate $=4.25$ ), likewise, strawberries coated with CS solution without sonication, show an increasing at decay rate (decay rate $=2$ ) as compared with strawberries coated CS NPs (decay rate $=1.5$ ). It is worth mentioning that the CS NPs stay stable throughout storage period Figure 8A. Moreover, CS NPs edible coating showed a significant ability to inhibit mold growth during 15 days of storage as shown in Figure 8B.

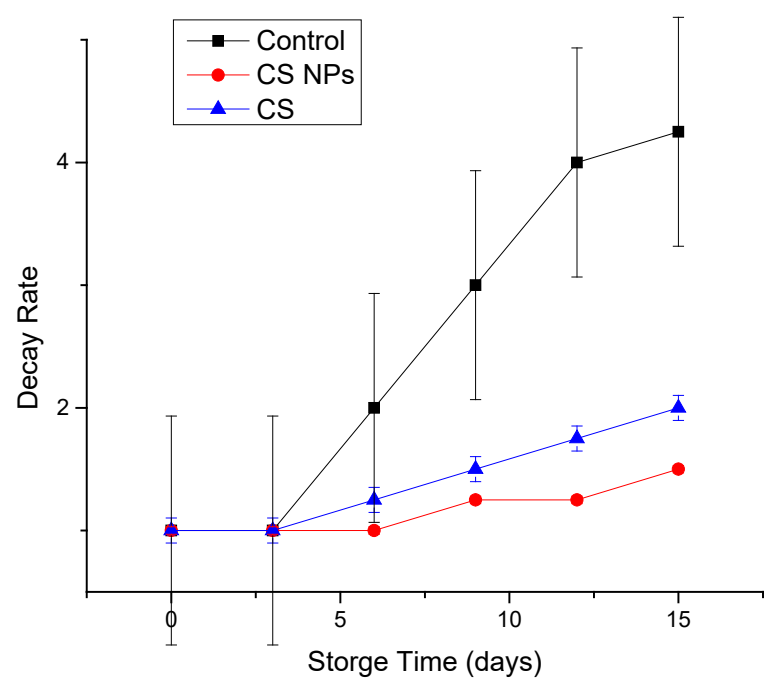

(A)

Figure 8. Cont. 


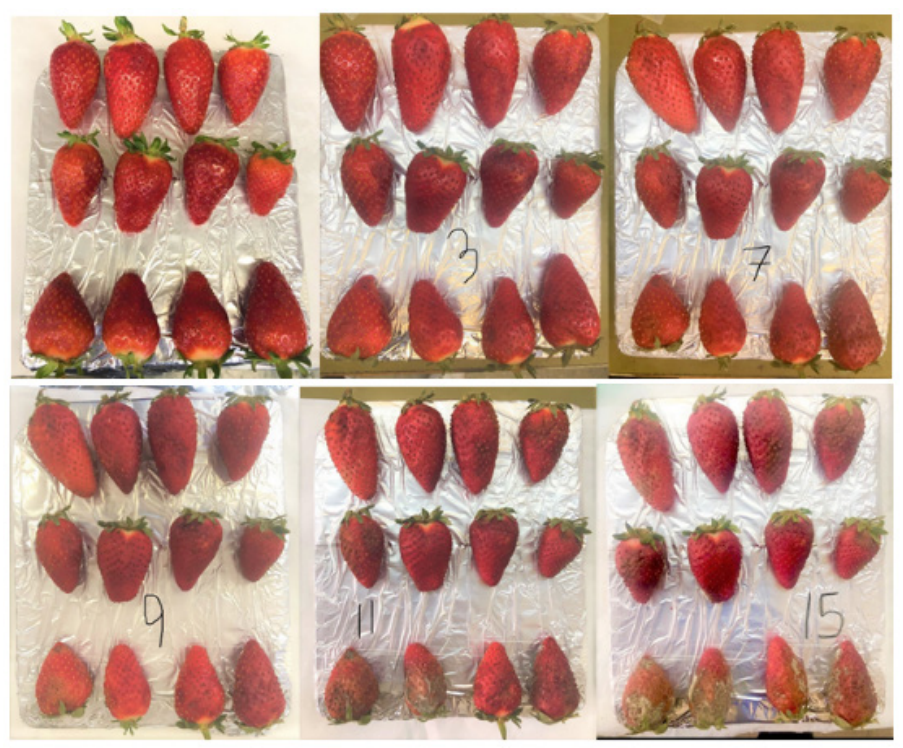

(B)

Figure 8. (A) Effect of CS NPs edible coating on decay rate of strawberries stored at $4{ }^{\circ} \mathrm{C}$. (B) Images of decay rate of strawberries throughout the storage. Up: Strawberries coated CS NPs, Down: Control strawberries (error bars indicate standard deviation).

\section{Conclusions}

The present study shows the effect of using sonochemical method in order to prepare edible nanoparticles of low MW chitosan to extend the shelf life of strawberries at cold storage of $4{ }^{\circ} \mathrm{C}$. Indeed, Nano-chitosan coatings impart antibacterial and antimold properties on fruit surfaces because they have a larger surface area and higher affinity with bacteria cells than the chitosan particles. The E-SEM images show the change in the morphology of the surface between coated and uncoated strawberries. The applications of edible nano coating reduced mass loss, growth of molds and delayed alteration of TSS and color of strawberries (red). Edible nano coating of chitosan helps at maintaining the L-ascorbic acid content during the storage period. Strawberries coated with CS NPs control the decay rate more significantly and efficiently compared to the control (uncoated strawberries). Strawberries treated with edible CS NPs coating accomplished a shelf-life of 15 days at cold storage. Thus, CS NPs have a great potential in strawberries preservation as an active edible coating. This leads to opening up new perspectives in future research in searching for an effective combination of CS NPs with other elemental forms to secure spacious antibacterial activity, preserve the quality and extending the shelf life of fruits.

Author Contributions: B.A.S. has conducted this research as part of his M.Sc. thesis. He was supervised by A.G. through his research work. All authors have read and agreed to the published version of the manuscript.

Funding: This research received no external funding.

Conflicts of Interest: The authors declare no conflict of interest.

\section{References}

1. Al-Naamani, L.; Dutta, J.; Dobretsov, S. Nanocomposite Zinc Oxide-Chitosan Coatings on Polyethylene Films for Extending Storage Life of Okra (Abelmoschus esculentus). Nanomaterials 2018, 8, 479. [CrossRef] [PubMed]

2. Lin, D.; Zhao, Y. Innovations in the Development and Application of Edible Coatings for Fresh and Minimally Processed Fruits and Vegetables. Compr. Rev. Food Sci. Food Saf. 2007, 6, 60-75. [CrossRef]

3. Trevino-Garza, M.Z.; Garcia, S.; Flores-Gonzalez, M.D.; Arevalo-Nino, K. Edible Active Coatings Based on Pectin, Pullulan, and Chitosan Increase Quality and Shelf Life of Strawberries (Fragaria ananassa). J. Food Sci. 2015, 80, M1823-M1830. [CrossRef]

4. Milena, P.; Francesco, M.; Maria, S.P.; Luigi, Z.; Elvira, N.; Giuseppe, C.; Marco, S. Effect of Chitosan Coating on the Postharvest Quality and Antioxidant Enzyme System Response of Strawberry Fruit during Cold Storage. Foods 2015, 4, 501-523. 
5. Hossein, B.; Ebrahim, A. Shelf life extension of strawberry by temperatures conditioning, chitosan coating, modified atmosphere, and clay and silica nanocomposite packaging. Sci. Hortic. 2018, 240, 496-508.

6. Luksiene, Z.; Buchovec, I. Impact of chlorophyllin-chitosan coating and visible light on the microbial contamination, shelf life, nutritional and visual quality of strawberries. Innov. Food Sci. Emerg. Technol. 2019, 52, 463-472. [CrossRef]

7. Duran, M.; Aday, M.S.; Zorba, N.N.D.; Temizkan, R.; Buyukcan, M.B.; Caner, C. Potential of antimicrobial active packaging 'containing natamycin, nisin, pomegranate and grape seed extract in chitosan coating' to extend shelf life of fresh strawberry. Food Bioprod. Process. 2016, 98, 354-363. [CrossRef]

8. Garcia, L.C.; Pereira, L.M.; Sarantopoulos, C.I.G.D.; Hubinger, M.D. Effect of Antimicrobial Starch Edible Coating on Shelf-Life of Fresh Strawberries. Packag. Technol. Sci. 2012, 25, 413-425. [CrossRef]

9. Hernandez-Munoz, P.; Almenar, E.; Del Valle, V.; Velez, D.; Gavara, R. Effect of chitosan coating combined with postharvest calcium treatment on strawberry (Fragaria ananassa) quality during refrigerated storage. Food Chem. 2008, 110, 428-435. [CrossRef] [PubMed]

10. Nadim, Z.; Ahmadi, E.; Sarikhani, H.; Chayjan, R.A. Effect of Methylcellulose-Based Edible Coating on Strawberry Fruit's Quality Maintenance During Storage. J. Food Process. Preserv. 2015, 39, 80-90. [CrossRef]

11. Garcia, C.; Pereira, L.M.; Sarantopoulos, C.I.G.D.; Hubinger, M.D. Selection of an Edible Starch Coating for Minimally Processed Strawberry. Food Bioprocess. Technol. 2010, 3, 834-842. [CrossRef]

12. Ribeiro, C.; Vicente, A.A.; Teixeira, J.A.; Miranda, C. Optimization of edible coating composition to retard strawberry fruit senescence. Postharvest Biol. Technol. 2006, 44, 63-70. [CrossRef]

13. Gomathi, T.; Supriya Prasad, P.; Sudha, P.N.; Anil, S. Size optimization and in vitro biocompatibility studies of chitosan nanoparticles. Int. J. Biol. Macromol. 2017, 104, 1794-1806.

14. Shichao, B.; Mengyang, W.; Liang, H.; Di, Q.; Xiaojie, C.; Xiguang, C. Evaluation of structure transformation and biocompatibility of chitosan in alkali/urea dissolution system for its large-scale application. Int. J. Biol. Macromol. 2020, 154, 758-764.

15. Gheorghe, A.M.; Mihaela, M.; Dan, C.V. The Use of Chitosan, Alginate, and Pectin in the Biomedical and Food SectorBiocompatibility, Bioadhesiveness, and Biodegradability. Polymers 2019, 11, 1837.

16. Milena, P.; Francesco, M.; Luigi, Z.; Elvira, N.; Giuseppe, C.; Marco, S. Effect of chitosan treatment on strawberry allergen-related gene expression during ripening stages. J. Food Sci. Technol. 2017, 54, 1340-1345.

17. Xing, Y.G.; Xu, Q.L.; Li, X.C.; Chen, C.K.; Ma, L.; Li, S.H.; Che, Z.M.; Lin, H.B. Chitosan-Based Coating with Antimicrobial Agents: Preparation, Property, Mechanism, and Application Effectiveness on Fruits and Vegetables. Int. J. Polym. Sci. 2016, $2016,1-24$. [CrossRef]

18. Chao, D.; Xin, M.; Jingru, M.; Iqbal Hassan, K.; Lei, D.; Avik, K.; Xingye, A.; Junhua, Z.; Tanzina, H.; Yonghao, N. Chitosan as A Preservative for Fruits and Vegetables: A Review on Chemistry and Antimicrobial Properties. J. Bioresour. Bioprod. 2019, 4, 11-21.

19. Theapsak, S.; Watthanaphanit, A.; Rujiravanit, R. Preparation of chitosan-coated polyethylene packaging films by DBD plasma treatment. ACS Appl. Mater. Interfaces 2012, 4, 2474-2482. [CrossRef]

20. Jiang, Y.; Yu, L.; Hu, Y.; Zhu, Z.; Zhuang, C.; Zhao, Y.; Zhong, Y. Electrostatic spraying of chitosan coating with different deacetylation degree for strawberry preservation. Int. J. Biol. Macromol. 2019, 139, 1232-1238. [CrossRef]

21. Chemat, F.; Khan, M.K. Applications of ultrasound in food technology: Processing, preservation and extraction. Ultrason. Sonochem. 2011, 18, 813-835. [CrossRef]

22. Agarwal, M.; Agarwal, M.K.; Shrivastav, N.; Pandey, S.; Das, R.; Gaur, P. Preparation of Chitosan Nanoparticles, and their In-vitro Characterization. Int. J. Life. Sci. Sci. Res 2018, 4, 1713-1720. [CrossRef]

23. Bangun, H.; Tandiono, S.; Arianto, A. Preparation and evaluation of chitosan-tripolyphosphate nanoparticles suspension as an antibacterial agent. J. Appl. Pharm. Sci. 2018, 8, 147-156.

24. Ramezani, Z.; Zarei, M.; Raminnejad, N. Comparing the effectiveness of chitosan and nanochitosan coatings on the quality of refrigerated silver carp fillets. Food Control 2014, 51, 43-48. [CrossRef]

25. Oh, J.W.; Chun, S.C.; Chandrasekaran, M. Preparation and in Vitro Characterization of Chitosan Nanoparticles and Their Broad-Spectrum Antifungal Action Compared to Antibacterial Activities against Phytopathogens of Tomato. Agronomy 2019, 9, 21. [CrossRef]

26. Perelshtein, I.; Ruderman, Y.; Perkas, N.; Beddow, J.; Singh, G.; Vinatoru, M.; Joyce, E.; Mason, T.J.; Blanes, M.; Molla, K.; et al. The sonochemical coating of cotton withstands 65 washing cycles at hospital washing standards and retains its antibacterial properties. Cellulose 2013, 20, 1215-1221. [CrossRef]

27. Perelshtein, I.; Ruderman, E.; Perkas, N.; Tzanov, T.; Beddow, J.; Joyce, E.; Mason, T.J.; Blanes, M.; Molla, K.; Patlolla, A.; et al. Chitosan and chitosan-ZnO-based complex nanoparticles: Formation, characterization, and antibacterial activity. J. Mater. Chem. $B$ 2013, 1, 1968-1976. [CrossRef]

28. Kiel, S.; Grinberg, O.; Perkas, N.; Charmet, J.; Kepner, H.; Gedanken, A. Forming nanoparticles of water-soluble ionic molecules and embedding them into polymer and glass substrates. Beilstein J. Nanotechnol. 2012, 3, 267-276. [CrossRef]

29. Perelshtein, I.; Applerot, G.; Perkas, N.; Guibert, G.; Mikhailov, S.; Gedanken, A. Sonochemical coating of silver nanoparticles on textile fabrics (nylon, polyester and cotton) and their antibacterial activity. Nanotechnology 2008, 19, 245705. [CrossRef]

30. Perelshtein, I.; Perkas, N.; Gedanken, A. The sonochemical functionalization of textiles. In The Impact and Prospects of Green Chemistry for Textile Technology; Woodhead Publishing: Cambridge, UK, 2019; pp. 161-198. 
31. Gottesman, R.; Shukla, S.; Perkas, N.; Solovyov, L.A.; Nitzan, Y.; Gedanken, A. Sonochemical Coating of Paper by Microbiocidal Silver Nanoparticles. Langmuir 2011, 27, 720-726. [CrossRef]

32. Kanikireddy, V.; Varaprasad, K.; Rani, M.S.; Venkataswamy, P.; Reddy, B.J.M.; Vithal, M. Biosynthesis of CMC-Guar Gum-Ag-0 nanocomposites for inactivation of food pathogenic microbes and its effect on the shelf life of strawberries. Carbohydr. Polym. 2020, 236, 116053. [CrossRef] [PubMed]

33. Al-Asmar, A.; Giosafatto, C.V.L.; Sabbah, M.; Sanchez, A.; Santana, R.V.; Mariniello, L. Effect of Mesoporous Silica Nanoparticles on The Physicochemical Properties of Pectin Packaging Material for Strawberry Wrapping. Nanomaterials 2019, 10, 52. [CrossRef] [PubMed]

34. Li, Y.Y.; Dong, Q.F.; Chen, J.W.; Li, L. Effects of coaxial electro spun eugenol loaded core-sheath PVP/shellac fibrous films on postharvest quality and shelf life of strawberries. Postharvest Biol. Technol. 2020, 159, 111028. [CrossRef]

35. Liu, Y.T.; Yuan, Y.; Duan, S.Q.; Li, C.; Bin, H.; Liu, A.P.; Wu, D.T.; Cui, H.Y.; Lin, L.; He, J.L.; et al. Preparation and characterization of chitosan films with three kinds of molecular weight for food packaging. Int. J. Biol. Macromol. 2020, 155, $249-259$. [CrossRef] [PubMed]

36. Wang, Y.; Li, R.; Lu, R.; Xu, J.; Hu, K.; Liu, Y. Preparation of Chitosan/Corn Starch/Cinnamaldehyde Films for Strawberry Preservation. Foods 2019, 8, 423. [CrossRef]

37. Shahzad, S.; Ahmad, S.; Anwar, R.; Ahmad, R. Pre-storage application of calcium chloride to improve the shelf life of straw berry. Pak. J. Agri. Sci 2020, 57, 339-350.

38. Niu, X.D.; Zhu, L.; Xi, L.J.; Guo, L.; Wang, H.S. An antimicrobial agent prepared by N-succinyl chitosan immobilized lysozyme and its application in strawberry preservation. Food Control 2020, 108, 106829. [CrossRef]

39. Emamifar, A.; Bavaisi, S. Nanocomposite coating based on sodium alginate and nano-ZnO for extending the storage life of fresh strawberries (Fragaria x ananassa Duch.). J. Food Meas. Charact. 2020, 14, 1012-1024. [CrossRef]

40. Rana, S.; Mehta, D.; Bansal, V.; Shivhare, U.S.; Yadav, S.K. Atmospheric cold plasma (ACP) treatment improved in-package shelf-life of strawberry fruit. J. Food Sci. Technol. 2019, 57, 102-112. [CrossRef]

41. Jiang, Y.; Yu, L.; Hu, Y.; Zhu, Z.; Zhuang, C.; Zhao, Y.; Zhong, Y. The preservation performance of chitosan coating with different molecular weight on strawberry using electrostatic spraying technique. Int. J. Biol. Macromol. 2020, 151, 278-285. [CrossRef]

42. Dewhirst, R.A.; Clarkson, G.J.J.; Rothwell, S.D.; Fry, S.C. Novel insights into ascorbate retention and degradation during the washing and post-harvest storage of spinach and other salad leaves. Food Chem. 2017, 233, 237-246. [CrossRef] [PubMed] 